\title{
Life cycle assessment of aquaculture systems-a review of methodologies
}

\author{
Patrik J. G. Henriksson • Jeroen B. Guinée • \\ René Kleijn • Geert R. de Snoo
}

Received: 18 February 2011 / Accepted: 9 December 2011 /Published online: 24 December 2011

(C) The Author(s) 2011. This article is published with open access at Springerlink.com

\begin{abstract}
Purpose As capture fishery production has reached its limits and global demand for aquatic products is still increasing, aquaculture has become the world's fastest growing animal production sector. In attempts to evaluate the environmental consequences of this rapid expansion, life cycle assessment (LCA) has become a frequently used method. The present review of current peer-reviewed literature focusing on LCA of aquaculture systems is intended to clarify the methodological choices made, identify possible data gaps, and provide recommendations for future development within this field of research. The results of this review will also serve as a start-up activity of the EU FP7 SEAT (Sustaining Ethical Aquaculture Trade) project, which aims to perform several LCA studies on aquaculture systems in Asia over the next few years.

Methods From a full analysis of methodology in LCA, six phases were identified to differ the most amongst ten peer-reviewed articles and two $\mathrm{PhD}$ theses (functional unit, system boundaries, data and data quality, allocation, impact assessment methods, interpretation methods). Each phase is discussed with regards to differences amongst the studies, current LCA literature followed by recommendations where appropriate. The conclusions and recommendations section reflects on aquaculture-specific scenarios as well as on some more general issues in LCA.
\end{abstract}

Responsible editor: José Potting

Electronic supplementary material The online version of this article (doi:10.1007/s11367-011-0369-4) contains supplementary material, which is available to authorized users.

P. J. G. Henriksson $(\bowtie) \cdot J$. B. Guinée • R. Kleijn • G. R. de Snoo Institute of Environmental Sciences (CML),

Department of Industrial Ecology, Leiden University,

2333 CC Leiden, the Netherlands

e-mail: henriksson@cml.leidenuniv.nl
Results Aquaculture LCAs often require large system boundaries, including fisheries, agriculture, and livestock production systems from around the globe. The reviewed studies offered limited coverage of production in developing countries, low-intensity farming practices, and non-finfish species, although most farmed aquatic products originate from a wide range of farming practices in Asia. Apart from different choices of functional unit, system boundaries and impact assessment methods, the studies also differed in their choice of allocation factors and data sourcing. Interpretation of results also differed amongst the studies, and a number of methodological choices were identified influencing the outcomes.

Conclusions and recommendations Efforts should be made to increase transparency to allow the results to be reproduced, and to construct aquaculture related database(s). More extensive data reporting, including environmental flows, within the greater field of LCA could be achieved, without compromising the focus of studies, by providing supporting information to articles and/or reporting only ID numbers from background databases. More research is needed into aquaculture in Asia based on the latest progress made by the LCA community.

Keywords Aquaculture · Fish · Food · LCA · Life cycle assessment $\cdot$ Review $\cdot$ Seafood

\section{Introduction}

Historical increases of yields from capture fisheries have been achieved by increasing fishing efforts and exploring new fishing grounds. Around 1990, however, global fish landings levelled off, followed by increases in fuel consumption as fishing boats had to cover larger distances to 
reach productive fishing grounds and greater efforts were required to maintain catches (Tlusty and Lagueux 2009; FAO 2010a). As a result of this development, aquaculture has become increasingly important in meeting the rising global demand for aquatic food products, with annual per capita supply from aquaculture growing from 0.7 to $7.8 \mathrm{~kg}$ globally since the 1970s (FAO 2010a). Farming methods for aquatic organisms are highly diverse, and 91\% of global production is based in Asia (FAO 2010b). Global aquaculture production is dominated by finfish ( $49 \%$ by weight), followed by aquatic plants $(23 \%)$, bivalves (19\%), and crustaceans (7\%) (FAO 2010b). Small-scale production of freshwater fish from ponds in Asia is the most common production system, with a general global trend towards intensification (Naylor et al. 2000; Muir 2005; FAO 2010a).

The rapid expansion of the aquaculture sector has been associated with many sustainability concerns, such as emissions leading to climate change, eutrophication, toxic and ecotoxic impacts, use of antibiotics, use of land and water needed for feed production, loss of biodiversity, introduction of non-indigenous species, spread/amplification of parasites and disease, genetic pollution, dependence on capture fisheries, and socio-economic concerns (Naylor et al. 2000; Pelletier et al. 2007; Pelletier and Tyedmers 2008; Ayer and Tyedmers 2009; Naylor et al. 2009). In the process of better understanding the environmental impacts of aquaculture, life cycle assessment (LCA) has become more frequently used to identify best practices and to assess overall environmental performance (Pelletier and Tyedmers 2008). As part of the EU FP7 SEAT project (Sustaining Ethical Aquaculture Trade, www.seatglobal.eu), LCA studies of shrimp, freshwater prawn, tilapia, and catfish will be performed in Bangladesh, Thailand, Vietnam, and China during the upcoming years. To provide a starting point for these studies, we have reviewed ten articles found in ISI Web of Knowledge (accessed on 30-Nov-2010) and two PhD theses focusing on LCA of aquaculture systems. Although several other studies are available, ${ }^{1}$ this review only focuses on peer-reviewed literature. The present review aims to clarify the methodological choices made, identify possible data gaps, and provide recommendations for future developments in this field of research, as well as for the upcoming SEAT' LCA studies.

\section{Materials and methods}

Originally developed for industrial production and processes, LCA was later applied to food products with the first LCA

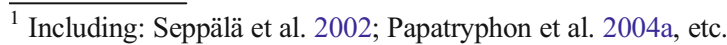

studies of food production being published in the early 1990s (Roy et al. 2009). These allowed for the first aquaculture LCAs, where agricultural and livestock systems provide resources for fish-feed production. The first published aquaculture-related LCA was done by Papatryphon et al. (2004b) in order to evaluate salmon feed. This was followed by a number of publications on aquaculture production in the second half of that decade (Table 1). The most productive institutes in this field of research have been the French INRA-IFREMER and Dalhousie University, Canada. Ten of the LCAs focused on finfish production, while Mungkung (2005) studied shrimp farming and Iribarren et al. (2010) examined mussel production. Of the ten finfish studies, nine focused on intensive production, and one (Phong 2010; Phong et al. 2011) described integrated semi-intensive farming systems. Six studies examined production systems based in Europe, three in Asia, and two in North America, while one study described global production.

Below, we discuss the LCA methodology that exhibited the greatest difference amongst the LCA studies listed in Table 1 (Guinée et al. 2002):

- Functional unit

- System boundaries

- Data and data quality

- Allocation

- Impact assessment methods

- Interpretation methods

The selection of these six phases is based on an analysis of all methodological assumptions and choices made and data sources adopted for the different steps of Goal and Scope definition, Inventory Analysis, Impact Assessment, and Interpretation. An analysis of other methodological phases and a detailed discussion of the impact categories are published as online resource to this article. Each of the six phases listed above is analyzed below in terms of differences amongst the studies, followed by a summary of the current LCA literature and, where appropriate, recommendations for research or harmonization.

\section{Results}

\subsection{Functional unit}

The functional unit is the reference unit used to quantify the performance of a production system (ISO 14044 2006). The most commonly used functional unit in the twelve studies reviewed here is 1 ton of live fish at the farm gate (six studies; see Table 1). Two other studies also limit themselves to the farm gate, with Grönroos et al. (2006) adopting dead weight and Phong (2010) adopting $1 \mathrm{kcal}$ alongside $1 \mathrm{~kg}$ as 


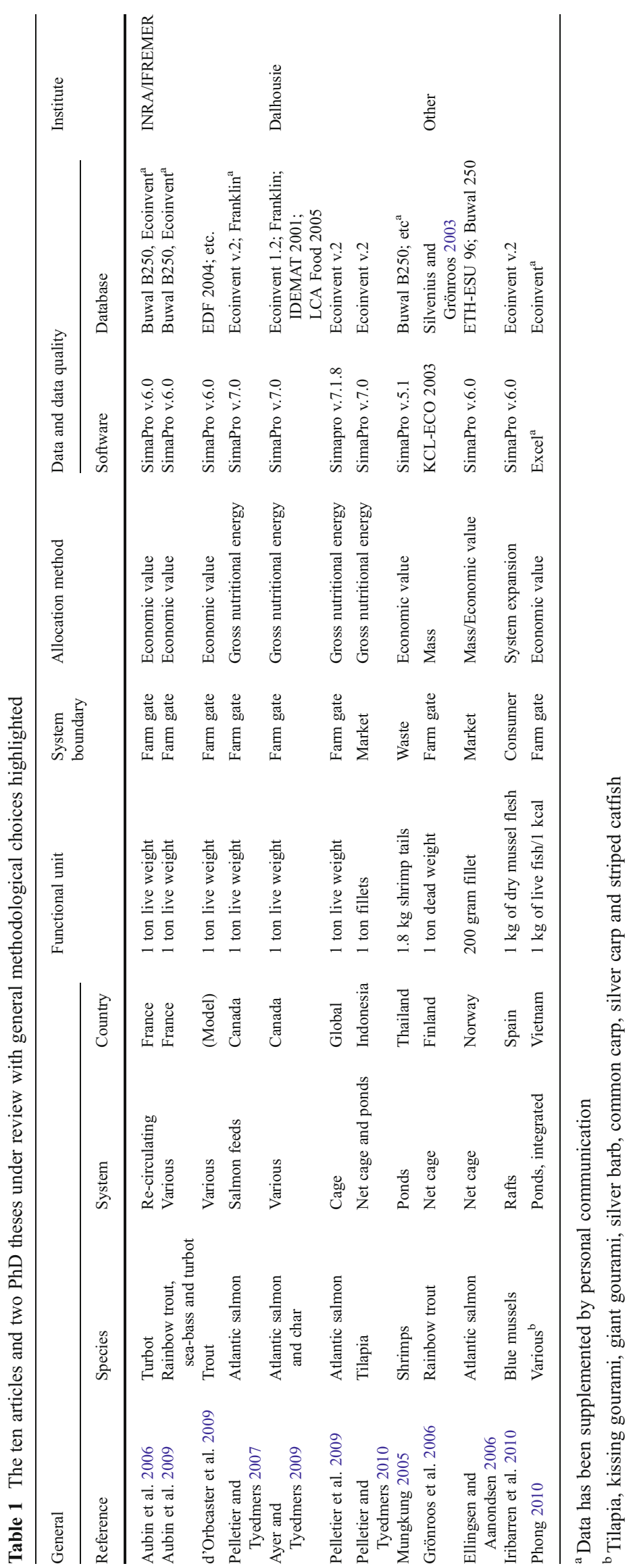


his two functional units. Four studies defined their functional unit in terms of edible yield, defined as the main part of the organism that was marketed (fillets, flesh, or tails).

The functional unit is the basis of comparison in comparative LCAs. The functional unit follows the goal of the study, since different goals may require different functional units. The goal of the study and the associated functional unit partially defines the system boundary of the inventory. For example, if frozen fillets in supermarkets are chosen as a functional unit, the system boundary needs to be defined so as to include processing, transportation, and distribution. The functional unit may, moreover, significantly influence comparative LCAs involving different species, since the edible portions and nutritional values of products can differ by an order of magnitude (Roy et al. 2009). Mussels and shrimp, for example, provide respectively, 13.6 and $140 \mathrm{~kg}$ of protein per ton of whole animals harvested (Mungkung 2005; Iribarren et al. 2010; www.nutraqua.com accessed 23-June-2010).

The choice of the functional unit is important for comparisons between species as well as across cultures, as the definition of edible will depend on cultural influenced consumer preferences. The choice of functional unit will also influence allocation decisions at the farm gate where more descriptive functional units, such as kilocalorie, may be more appropriate for comparisons between multi-output systems (Phong 2010). We therefore recommended to carefully choose a functional unit tailored to the goal and scope of the study.

\subsection{System boundaries}

The system boundary determines which unit processes will be included within an LCA study and which ones are to be excluded. With respect to the diverse goals of the reviewed studies, few have considered supply chain impacts beyond the farm gate (Pelletier and Tyedmers 2010). Iribarren et al. (2010), however, did include the whole production chain and found that a significant part of the emissions from mussel production is related to processing and marketing, with dispatch centers contributing significantly to the overall emissions from live mussel production. Infrastructure is also often excluded, due to the large amount of time that has to be invested in calculating the total input in relation to the small impact that is considered (Ayer and Tyedmers 2009). Where included and distinguished (Aubin et al. 2006; Ayer and Tyedmers 2009; Aubin et al. 2009; d'Orbcaster et al.
2009), however, infrastructure was found to contribute between $0 \%$ and $19.0 \%$ to the overall impacts in terms of global warming, eutrophication, and acidification indicators. Common cut-offs were based on the outcomes of previous studies, selection of impact categories, available data, and resource constraints (Mungkung 2005; Ellingsen and Aanondsen 2006; Grönroos et al. 2006; Pelletier et al. 2009; Pelletier and Tyedmers 2010).

The selection of the system boundary should be consistent with the goal of the study, and the criteria used to establish the system boundary should be identified and explained (ISO 14044 2006). In aquaculture systems, the length of the full production chain is largely dependent on the type of system (Fig. 1). For example, external inputs of feed and hatchery-reared juveniles may not be needed in extensive systems and if the product is sold fresh on the market it needs no processing (e.g., carp in China). Fish and seafood are also the most perishable of food products, and the level of processing will influence the longevity of the product, as well as the amounts wasted, hence the environmental impacts (Sonesson et al. 2005).

The problem in defining cut-offs for the quantification of inventories is a lack of readily accessible data, implying disproportionate expenditure of funds and efforts on data collection. Limitations of time, funds, or data access will inevitably lead to the exclusion of processes and to less complete and accurate results. Nowadays, it is, however, possible to handle the cut-off problem better, by estimating the environmental interventions associated with flows for which no readily accessible data is available using environmentally extended input-output analysis (EIOA) (Suh et al. 2004). For the purpose of consumer guidance, we recommend a more extensive system boundary at or beyond the market, as impacts may otherwise be underestimated (Iribarren et al. 2010). Further efforts should also be directed towards expanding current knowledge about the contributions from infrastructure, as this has been reported to have a larger influence on agriculture than on most other industrial processes (Frischknecht et al. 2007).

\subsection{Data and data quality}

Although all of the studies reviewed here model relevant agriculture, fisheries and other related processes - to different extents - most of the inventory details of these modeling efforts remain unpublished. Articles that do extensively report
Fig. 1 Simplified flow chart of aquaculture production. The inclusion of some processes (dashed lines) are dependent upon the system in focus

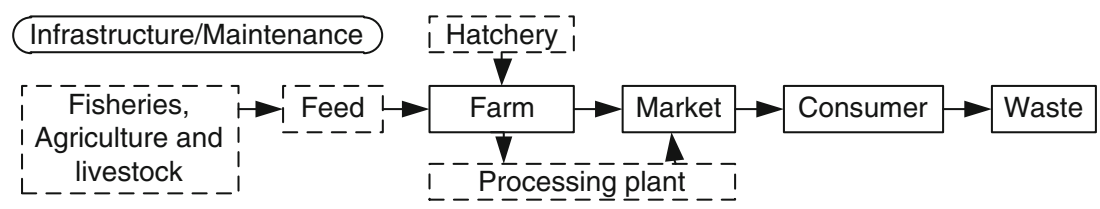


the data mainly specify economic flows, with environmental flows often limited to nutrient balances. This may be due to the aquaculture-based background of most of the researchers for whom eutrophication has historically been a major concern. In various articles, it remains unclear whether background databases were used or whether real foreground data (site-samples) had been collected (ILCD 2010); neither is it always clear which processes that were included in the study. Consequently, reproducing their results is difficult or impossible. For example, Ellingsen and Aanondsen (2006) reported: "Data are generally collected from various sources by both literature surveys, a study of available data sources, telephone conversations, and meetings". This, unfortunately, provides no clue as to which processes, data, or data sources were included in the study.

Background data used in the studies were derived from a wide range of databases, including some which were quite out-dated (ETH 1996 and BUWAL 250) (see Table 1). Some authors used combinations of different databases or did not clearly specify the precise database(s) consulted. Several studies, for example, reported that they had used SimaPro software, with all of the databases included in it. As SimaPro includes many different databases (e.g., Ecoinvent, US LCI database, US IO dbase, Danish IO dbase, Dutch IO dbase, LCA food dbase, Industry data, Japanese IO dbase, IVAM dbase; see http://www.pre.nl/ simapro/inventory_databases.htm), the actual data sources used in these studies remain unclear. All studies, moreover, rely on European databases (commonly different versions of Ecoinvent), even though various studies dealt with aquaculture in non-European countries. Although the authors of several studies did invest much effort in adapting inventories to regional conditions, there remains a real need for databases representing technologies of developing countries.

The focus of the studies ranged from single farms (Aubin et al. 2009; Ayer and Tyedmers 2009) to small samples of each farming system (Phong 2010), to aggregated industry averages representing significant parts of national outputs (Pelletier et al. 2009; Pelletier and Tyedmers 2010). However, the quality of foreground data available for aquaculture systems often depends on the intensity of the system and the region of data collection. Highly intensive systems, such as land-based salmon systems, often keep more complete records of all inputs and outputs, while only general estimations are available for most extensive pond systems in rural areas. Accessibility to feed inventories may, moreover, be subject to the scale and nature of the feed mill, as exact mixtures of ingredients often are held confidential. Site-specific measurements are, moreover, dependent on the resources available. The articles offer limited reporting on other environmental flows beyond nutrient budgets (including methane, nitrous oxide emissions, copper-based anti-fouling agents, antibiotics, etc.).
The International Organization for Standardization (ISO 14044 2006) states that data quality requirements should be specified to enable the goal and scope of the LCA to be met, and also that the treatment of missing data should be documented, and that data sources as well as an assessment of the reproducibility of the study results by independent practitioners should be addressed as part of the data quality requirements. ISO does not, however, demand publication of all data used.

Transparency in the reporting of data and reproducibility of results are important for proper peer-reviewing and interpretation of background data, at least to the extent that this is possible with regards to sensitive industry inventory data. A good example of the way data can be published without compromising the focus of the article was given by Grönroos et al. (2006) and Pelletier et al. (2009), who both published supporting documents describing inventories (although with different coverage of environmental data; see above), core processes, assumptions, and calculations. Another solution to fitting large inventories to the often restricted format of scientific journals is to report which processes derived from a background database (e.g., ecoinvent) were included in the study without actually including the data of that process. Such processes could simply be reported using the process ID numbers, rather than the full process names. This kind of more open reporting of data is critical for developing specific LCA data sets for aquaculture-related processes, as much primary data currently are lost by aggregating results and by only presenting impacts, rather than inventories. It should, however, be pointed out that the data sourcing and reporting issues discussed here are not unique to aquaculture LCAs, but rather apply to the majority of LCA studies published, whether peer-reviewed or not.

\subsection{Allocation}

Some of the main differences amongst the studies reviewed here are related to allocation. While all of the most commonly applied procedures for allocation (including mass, economic value, gross energetic content, and system expansion) have been applied to aquaculture LCAs, economic value and gross nutritional energy content have more frequently been used in the more recent publications (see Table 1). This is also the main methodological difference between the two main publishing institutions, with INRA-IFREMER applying economic allocation, while researchers at Dalhousie University commonly prefer gross energy content as the basis for allocation (see Table 1).

Four publications applied system expansion to certain allocation situations (Ayer and Tyedmers 2009; Pelletier et al. 2009; Pelletier and Tyedmers 2010; Iribarren et al. 2010). Iribarren et al. (2010), for example, used system expansion 
for Spanish mussel production (with mussel as the main product and shells as a co-product) with the assumption that mussel shells could be used to replace conventional calcium carbonate production. Grönroos et al. (2006) restricted their analysis to whole fish at the farm gate to avoid allocation in the processing phase, while mass allocation was used for feed inputs. Some authors did not report their allocation decisions in their articles.

Most industrial processes yield more than one product, and some recycle expanded products as raw materials. As a result, the materials and energy flows, as well as the associated environmental releases, have to be allocated to the different products according to clearly stated and justified procedures. In aquaculture, many of the feed inputs are co-produced in other production systems (e.g., rice bran, fisheries by-catch, and co-products from livestock processing), and co-products also occur in the processing phase.

It is our belief that the multi-functionality problem is an artefact of the desire to isolate one function out of many and as artefacts can only be resolved in an artificial way, there will always be more than one way of solving the multifunctionality problem. This is illustrated by the debate on methods to deal with the multi-functionality problem over the last two to three decades which still has not provided a generally accepted method. Depending on the application (e.g., policy or scientific publications), using alternative allocation methods could be seen as an opportunity to produce more realistic ranges of results and provide stronger conclusions. There are, however, certain requirements that need to be addressed when dealing with allocation issues, such as that the solution should be consistent, well justified and in-line with main methodological principles (Guinée et al. 2004; ILCD 2010). It is also important to always report on the allocation method(s) applied and perform a sensitivity analysis, as allocation plays a pivotal role in the performance of a production system (ISO 14044 2006).

\subsection{Life cycle impact assessment methods}

All reviewed studies applied one or more life-cycle impact assessment methods. The major impact assessment methodology used for characterization was the midpoint CML baseline method (Guinée et al. 2002) with only Ellingsen and Aanondsen (2006) applying an endpoint approach (eco-indicator 99 method; Goedkoop and Spriensma 1999). Grönroos et al. (2006) choose to use region-specific characterization factors for eutrophication and acidification, while making a distinction between aquatic and terrestrial emissions. Only climate change, acidification, and eutrophication were adopted as impact categories by all studies. In addition, a few novel methods were introduced for biotic resource use, water dependency, and land (surface) use (Table 2).
As regards climate change, the characterization factors suggested by the international panel on climate change (IPCC; Houghton et al. 2001) were the basis for all reviewed studies. This therefore enables for valid conclusions to be drawn amongst the studies, e.g., the great importance of feed inputs for aquaculture systems.

As regards acidification, all but three studies adopted the approach developed by Huijbregts (1999a). Apart from Ellingsen and Aanondsen (2006) and Grönroos et al. (2006), Phong (2010) chose alternative characterization factors, in this case, the older Heijungs et al. (1992) acidification method.

As regards eutrophication, similar differences are found as for acidification, while Grönroos et al. (2006) chose to separate terrestrial and aquatic emissions due to their distinct association to feed production and feed application, respectively. Phong (2010), again, refers to an older alternative publication, Weidema et al. (1996).

Cumulative primary fossil energy demand was the fourth most commonly included impact category amongst the studies and showed a large overlap with abiotic resource depletion (Ayer and Tyedmers 2009). Strikingly, six studies adopted and quantified a novel impact category, biotic resource use. Its use aims to capture the ultimate carbon-based energy stemming from biological systems that support fed aquaculture production, although a standardized protocol for this impact category still remains to be developed (Pelletier et al. 2007). Marine exotoxicity, an impact category for which the existing characterization methods have been widely debated within the LCA community (Pettersen and Hertwich 2008; Gloria et al. 2006), was adopted and quantified in four studies. A range of other toxicity related impact categories were less frequently adopted, along with abiotic resource depletion and ozone depletion. Water dependency and land use were represented in only two studies each, using own methodology. Little consideration was, however, given to the type of water use (e.g., marine or freshwater, degradative or consumptive; Bayart et al. 2010) on either the input or the output side, nor were emissions relating to land use and transformation considered (ILCD 2010). Other concerns not covered by the LCA methodologies reported in our review include impacts on the seafloor from capture fisheries, the introduction of invasive species, the spread of diseases, genetic pollution, and socio-economic concerns (Pelletier et al. 2007).

In summary, the current review of aquaculture LCAs shows that impact assessment methodologies have been applied to all studies reviewed. The range of impact categories covered is, however, limited, and the methods adopted for the various categories differ, hampering comparisons of study results. Some authors used old characterization factors, while others developed their own quantification methods. Future harmonization with the developments 
Table 2 Frequency of applying different impact categories in LCA studies on aquaculture and the impact assessment method used.

\begin{tabular}{|c|c|c|}
\hline Impact category & $\Sigma$ & Impact assessment method \\
\hline Global warming potential & 12 & Houghton et al. $2001(1,2,3,4,5,6,7,8,9,10,11,12)$ \\
\hline Acidification & 12 & $\begin{array}{l}\text { Huijbregts 1999a(1, 2, 5, 6, 7, 8, 9, 10, 11); Goedkoop and Spriensma } 1999 \text { (3); } \\
\text { Seppälä et al. } 2006 \text { (4); Heijungs et al. } 1992 \text { (12) }\end{array}$ \\
\hline Eutrophication & 12 & $\begin{array}{l}\text { Heijungs et al. } 1992(1,2,5,6,7,8,9,10) \text {; Goedkoop and Spriensma } 1999(3) \text {; } \\
\text { Weidema et al. } 1996(12) \text {, Seppälä et al. } 2004(4)^{\mathrm{a}} \text {; Seppälä et al. } 2006(4)^{\mathrm{a}}\end{array}$ \\
\hline Energy use & 8 & VDI 1997 (2, 5, 6, 7, 8, 9, 11); Goedkoop and Spriensma 1999 (3); Article specific (12) \\
\hline Biotic resource use & 6 & Papatryphon et al. 2004b (2, 6, 8); Pelletier and Tyedmers $2007(5,9,11)$ \\
\hline Marine aquatic ecotoxicity & 4 & Huijbregts 1999b $(5,7,10)$; Meent and Klepper $1997(3)^{\mathrm{b}}$ \\
\hline Abiotic depletion potential & 3 & Guinée and Heijungs $1995(1,7,10)$ \\
\hline Ozone depletion potential & 3 & WMO $1999(1,10)$; Goedkoop and Spriensma 1999 (3) \\
\hline Human toxicity & 3 & Huijbregts $1999 \mathrm{~b}(1,7,10)$ \\
\hline Water dependence & 2 & Own methodology $(6,8)$ \\
\hline Photochemical oxidant formation & 2 & Derwent et al. 1998/Jenkin and Hayman $1999(1,10)$ \\
\hline Freshwater aquatic ecotoxicity & 2 & Meent and Klepper 1997 (3) ${ }^{\text {b }}$ Huijbregts 1999b (10) \\
\hline Terrestrial ecotoxicity & 2 & Meent and Klepper $1997(3)^{\text {b }}$; Huijbregts 1999b (10) \\
\hline Surface use & 2 & Own methodology $(8,12)$ \\
\hline Respiratory impacts from inorganics & 1 & Goedkoop and Spriensma 1999 (3) \\
\hline Carcinogenic effects on humans & 1 & Goedkoop and Spriensma 1999 (3) \\
\hline
\end{tabular}

Global warming, acidification and eutrophication were the only impact categories applied by all authors. References: (1) Mungkung 2005; (2) Aubin et al. 2006; (3) Ellingsen and Aanondsen 2006; (4) Grönroos et al. 2006; (5) Pelletier and Tyedmers 2007; (6) Aubin et al. 2009; (7) Ayer and Tyedmers 2009; (8) d'Orbcaster et al. 2009; (9) Pelletier et al. 2009; (10) Iribarren et al. 2010; (11) Pelletier and Tyedmers 2010; (12) Phong 2010. For full references on the impact assessment methods, please refer to the Online Resource (ESM)

${ }^{a}$ Aquatic and terrestrial eutrophication was reported separately

${ }^{\mathrm{b}}$ Ecotoxicity is summarized under one category

within the LCA community is therefore advised, focusing on the standardization efforts promoted by ILCD (the European Commission's Join Research Centre) and UNEPSETAC (the United Nations Environment Programme and the Society of Environmental Toxicology and Chemistry) including the ILCD handbook (lct.jrc.ec.europa.eu), USEtox ${ }^{\mathrm{TM}}$ (www.usetox.org), land-use (lcinitiative.unep.fr, accessed: 17-Oct-2010) and freshwater use (Bayart et al. 2010) (for a complete overview of the life cycle impact assessment methods adopted by the different studies reviewed here, please see the Online Resource (ESM) to this paper).

\subsection{Interpretation methods}

Although all studies performed a dominance or contribution analysis, many did not perform a complete set of sensitivity analyses, as is required by the current ISO standards. Ayer and Tyedmers (2009), however, conducted an extensive set of sensitivity analyses, one of which highlighted the importance of electricity sourcing. Another study by Pelletier and Tyedmers (2007) concluded that allocation factors strongly influence the impact of different feed inputs. Both d'Orbcaster et al. (2009) and Pelletier et al. (2009) drew a parallel between food conversion ratios (FCRs, defined as kilogram dry feed/kilogram live fish) and GHG (greenhouse gas) emissions, while Mungkung (2005) supported her conclusions by performing a sensitivity analysis on data assumptions for fishing practices as well as for different impact assessment methods. Ellingsen and Aanondsen (2006) also used two alternative impact assessment methods to strengthen their conclusions. Pelletier et al. (2009) evaluated the range of nitrous oxide emissions from nitrogen fertilizers, compared to the default value indicated by the IPCC. Only Phong (2010) applied statistical tools to different farming practices, in the form of one-way ANOVA (analysis of variance).

According to ISO (2006), the life cycle interpretation phase of an LCA comprises the identification of the significant issues based on the results of the LCI (life cycle inventory) and LCIA stages, an evaluation involving completeness, sensitivity, and consistency checks, and finally the formulation of conclusions, limitations, and recommendations. It is an important phase of any LCA study, where any weaknesses should be highlighted and results critically tested.

Irregularities at temporal and spatial scales give rise to deviations in inventories of aquaculture production. Underlying models, moreover, rely on assumptions and 
methodological choices influence the results. Statistical tools and sensitivity analyses are therefore important to strengthen the arguments and conclusions in aquaculture LCAs. Treating farms individually, rather than as averages, would here allow for more extensive statistical comparisons to be made between farms. Known pivotal factors identified in the articles reviewed here include various inventory choices (feeds, raw materials, infrastructure, etc.), GHG emissions from agricultural fields and aquatic systems, nitrogen and phosphorus emissions, allocation factors, and characterization factors. Further efforts are therefore needed to account for the many degrees of freedom, using more extensive sensitivity analyses and implementing, e.g., Monte Carlo analysis.

\section{Discussion}

Aquaculture is currently the fastest growing animal production sector, and ever larger amounts of farmed aquatic products are being traded on international markets. Increasing concerns about the sustainability of production have, however, been raised, and the standards and requirements imposed on the aquaculture sector are becoming ever stricter. In the search for best practice, LCA has proved to be a valuable tool to identify environmental hot spots and compare different production systems. To date, however, there has been limited LCA coverage of the various farming systems worldwide, especially in Asia from where the bulk of farmed aquatic products originate. The present review has identified a range of methodological and data sourcing approaches reported in existing publications, where methodological choices often govern the outcomes.

Nine of the twelve peer-reviewed publications included in this review focused on intensive finfish production, which represents a small share of the global aquaculture output. Eight of the studies were, moreover, limited to whole fish at the farm gate, which may give misleading results if consumer guidance is the objective. Distribution of fish and seafood to markets may, for example, contribute disproportionately to the overall impacts as these are highly perishable commodities with high value attached to their freshness (Tlusty and Lagueux 2009). More LCA-based research is therefore needed to guide this still expanding sector towards best practice. With the wide-spread of aquaculture in Asia, these studies should focus on Asian aquaculture and alternative farming practices, using a functional unit relevant to the aim of the study.

The greatest single methodological difference amongst the studies was in allocation, with monetary value and gross energy content being the most commonly applied allocation factors. However, the level of reasoning and consistency regarding choices made varied greatly amongst studies. As consensus, let alone scientific clarity, is not likely to be achieved soon, allocation choices should be clearly defined and justified. Inventory results with regard to the allocation method adopted should also be supported by thorough sensitivity analysis, as advocated by ISO. Databases and software should, moreover, simplify the application of alternative allocation decisions to enable more extensive sensitivity analyses.

All studies had adopted the IPCC recommendations for global warming, as it represents a highly resourceful centralized scientific body. Similar developments should be encouraged for other impact categories, following initiatives by ILCD and UNEP-SETAC. However, inventories of the characterized environmental flows need to be made available to allow alternative characterization factors to be implemented. Toxicological implications should also be given more attention as they have historical importance in the aquaculture sector (e.g., Malachite green). New characterization factors and standardized protocols need to be developed to address more aquaculture-specific concerns (e.g., seafloor disturbance and biotic resource use). A distinction between terrestrial and aquatic eutrophication may also have to be made, as these emissions usually have distinctly different origins.

\section{Conclusions and recommendations}

There is a need for more detailed LCA studies of non-finfish species, as well as of integrated, extensive, and semiintensive production of finfish in developing countries (especially in Asia), in order to guide the industry towards best practice, highlight hot spots, and guide consumers. These studies should conform to up-to-date guidelines from, e.g., ISO, ILCD, and SETAC-UNEP in order to move towards a more harmonized methodology. The characterization factors and background databases selected should also be the latest available versions. There is also a need to develop impact categories more specifically related to aquaculture, such as seafloor disturbance, biotic resource depletion, and loss of biodiversity. Moreover, the reporting of methodological choices and data should be improved to allow for comprehensive critical analysis and the joint development of extensive inventories.

Sourcing of background data should be consistent and give consideration to the underlying methodological and geographical characteristics of the database used. More extensive reporting of inventory data as online resource and by defining process numbers is also recommended, as well as efforts to extend the coverage of environmental flows. This would assist the development of specific data (and databases) for aquaculture practices and feeds, which would further promote the quantity and quality of aquaculture LCAs. Finally, the contribution of infrastructure seems to be strongly 
influenced by the methodology and impact categories used, while applying EIOA to aquaculture systems would allow the importance of missing data in aquaculture LCAs to be estimated. Many of the improvement options mentioned here can be implemented by increasing knowledge exchange between the aquaculture community, from which most of the reviewed studies originate, and the LCA community.

In the ongoing SEAT project, the ambition over the coming years is to describe four major aquaculture exports farmed in Asia. Detailed LCAs will be conducted of a representative sample of each major farming system, supported by a larger scoping survey collecting basic data for 1,600 grow-out farmers in the region. Foreground data will also be collected on other actors in the value chain, including feed producers, processing plants, hatcheries, nurseries, and fishmeal factories in each country. The results of this research are to be presented in inventory and impact assessment reports over the upcoming years, with the ambition to adopt the recommendations suggested above. These efforts together with several other LCA studies published after this review (e.g., Bosma et al. 2011; Cao et al. 2011) will hopefully improve our current knowledge of the impacts of the aquaculture sector and promote best practice.

Acknowledgements This work is part of the Sustaining Ethical Aquaculture Trade (SEAT) project, which is co-funded by the European Commission within the Seventh Framework Programme-Sustainable Development Global Change and Ecosystem (project no. 222889). www.seatglobal.eu.

Open Access This article is distributed under the terms of the Creative Commons Attribution Noncommercial License which permits any noncommercial use, distribution, and reproduction in any medium, provided the original author(s) and source are credited.

\section{References}

Aubin J, Papatryphon E, van der Werf HMG, Petit J, Morvan YM (2006) Characterisation of the environmental impact of a turbot (Scophtalmus maximus) re-circulating production system using Life Cycle Assessment. Aquaculture 261:1259-1268

Aubin J, Papatryphon E, van der Werf HMG, Chatzifotis S (2009) Assessment of the environmental impact of carnivorous finfish production systems using life cycle assessment. J Clean Prod $17: 354-361$

Ayer NW, Tyedmers PH (2009) Assessing alternative aquaculture technologies: life cycle assessment of salmonid culture systems in Canada. J Clean Prod 17:362-373

Bayart J-B, Bulle C, Deschênes L, Margini M, Pfister S, Vince F, Koehler A (2010) A framework for assessing off-stream freshwater use in LCA. Int J Life Cycle Assess 15:439-453

Bosma R, Anh PT, Potting J (2011) Life cycle assessment of intensive striped catfish farming in the Mekong Delta for screening hotspots as input to environmental policy and research agenda. Int J Life Cycle Assess 9:903-915

Cao L, Diana JS, Keoleian GA, Lai Q (2011) Life cycle assessment of Chinese shrimp farming systems targeted for export and domestic sales. Environ Sci Technol 45:6531-6538
d'Orbcaster RE, Blancheton J-P, Aubin J (2009) Towards environmentally sustainable aquaculture: comparison between two trout farming systems using life cycle assessment. Aquacult Eng 40:113-119

Derwent RG, Jenkin ME, Saunders SM, Pilling MJ (1998) Photochemical ozone creation potentials for organic compounds in Northwest Europe calculated with a master chemical mechanism. Atmos Environ 32:2429-2441

Ellingsen H, Aanondsen SA (2006) Environmental impacts of wild caught cod and farmed salmon - a comparison with chicken. Int $\mathrm{J}$ Life Cycle Assess 1:60-65

FAO (2010a) State of world fisheries and aquaculture 2010. Rome, Italy

FAO Fisheries and Aquaculture Information and Statistics Service (2010b) Aquaculture production 1950-2008. Available at: http://www.fao.org/fishery/statistics/software/fishstat/en

Frischknecht R, Althaus H-J, Bauer C, Doka G, Heck T, Jungbluth N, Kellenberger D, Nemecek T (2007) The environmental relevance of capital goods in life cycle assessments of products and services. Int J Life Cycle Assess 12:7-17

Gloria TP, Russell AJ, Atherton J, Baker SR, Cook M (2006) Ecological toxicity methods and metals - an examination of two case studies. Int J Life Cycle Assess 11:26-33

Goedkoop M, Spriensma R (1999) The Eco-indicator 99-A damage oriented method for Life Cycle Impact Assessment-Methodology Report, PRé Consultants. Amersfoort, Netherlands. Available at: http://www.pre.nl/eco-indicator99/ei99-reports.htm

Grönroos J, Seppälä J, Silvenius F, Mäkinen T (2006) Life cycle assessment of Finnish cultivated rainbow trout. Boreal Environ Res 11:401-414

Guinée JB, Heijungs R (1995) A proposal for the definition of resource equivalency factors for use in product life-cycle assessment. Environ Toxicol Chem 14:917-925

Guinée JB, Gorrée M, Heijungs R, Huppes G, Kleijn R, de Koning A, van Oers L, Sleeswijk AW, Sangwon S, Udo de Haes HA, de Bruijn JA, van Duin R, Huijbregts MAJ (2002) Handbook on life cycle assessment: operational guide to the ISO standards. Kluwer Academic Publishers, Dordrecht

Guinée JB, Heijungs R, Huppes G (2004) Economic allocation: examples and derived decision tree. Int $\mathrm{J}$ Life Cycle Assess 9:23-33

Heijungs R, Guinee JB, Huppes G, Lankreijer RM, Udo De Haes HA, Wegener Sleeswijk A, Ansems AMM, Eggels PG, van Duin R, De Goede HP (1992) Environmental lift-cycle assessment of products. CML, Leiden University, Leiden, The Netherlands, Guide and Backgrounds

Houghton JT, Ding Y, Griggs DJ, Noguer M, van der Linden PJ, Dai X, Maskell K, Johnson CA (2001) Climate Change 2001: The Scientific Basis, Intergovernmental Panel on Climate Change (IPCC). Cambridge Univ Press, Cambridge, UK

Huijbregts MAJ (1999a) Life cycle impact assessment of acidifying and eutrophying air pollutants. Interfaculty Department of Environmental Science, Faculty of Environmental Science, University of Amsterdam, Calculations of equivalency factors with RAINS-LCA

Huijbregts MAJ (1999b) Priority assessment of toxic substances in LCA - development and application of the multi-media fate, exposure and effect model USES-LCA. University of Amsterdam, IVAM environmental research

ILCD - International Reference Life Cycle Data System Handbook (2010) Analysis of existing environmental impact assessment methodologies for use in life cycle assessment. JRC, European Commission

Iribarren D, Moreira MT, Gumersindo F (2010) Revisiting the life cycle assessment of mussels from a sectorial perspective. J Clean Prod 18:101-111 
ISO 14044 - International Organization for Standardization (2006) Environmental management - life cycle assessment - requirements and guidelines (ISO 14044:2006). International Organization for Standardization, Geneva, Switzerland

Jenkin ME, Hayman GD (1999) Photochemical ozone creation potentials for oxygenated volatile organic compounds: sensitivity to variations in kinetic and mechanistic parameters. Atmos Environ 33:1275-1293

Meent D van de, Klepper O (1997) Mapping the potential affected fraction (PAF) of species as an indicator of generic toxic stress, RIVM report 607504001 , Bilthoven

Muir J (2005) Managing to harvest? Perspectives on the potential of aquaculture. Phil Trans Roy Soc B 360:191-218

Mungkung RT (2005) Shrimp aquaculture in Thailand: application of life cycle assessment to support sustainable development. Ph.D. thesis. Center for Environmental Strategy, School of Engineering, University of Surrey, Surrey, UK

Naylor RL, Goldburg RJ, Primavera JH, Kautsky N, Beveridge MCM, Clay J, Folke C, Lubchenco J, Mooney H, Troell M (2000) Effect of aquaculture on world fish supplies. Nature 405:1017-1024

Naylor RL, Hardy RW, Bureau DP, Chiu A, Elliott M, Farrell AP, Forster I, Gatlin DM, Goldburg RJ, Hua K, Nichols PD (2009) Feeding aquaculture in an era of finite resources. Proc Natl Acad Sci 106:15103-15110

Papatryphon E, Petit J, van der Werf HMG (2004a) The development of life cycle assessment for the evaluation of rainbow trout farming in France. In: Halberg N (ed) Life cycle assessment in the agri-food sector. Proceedings from the 4th international conference. Danish Institute of Agricultural Sciences, Horsens, pp 73-80

Papatryphon E, Petit J, Kaushik SJ, van der Werf HMG (2004b) Environmental impact assessment of salmonid feeds using life cycle assessment (LCA). Ambio 33:316-323

Pelletier NL, Tyedmers PH (2007) Feeding farmed salmon: is organic better? Aquaculture 272:399-416

Pelletier NL, Tyedmers PH (2008) Life cycle considerations for improving sustainability assessments in seafood awareness campaigns. Environ Manage 42:918-941

Pelletier N, Tyedmers PH (2010) A life cycle assessment of frozen Indonesian tilapia fillets from lake and pond-based production systems. J Ind Ecol 14:467-481

Pelletier NL, Ayer NW, Tyedmers PH, Kruse SA, Flysjo A, Robillard G, Ziegler F, Scholz AJ, Sonesson U (2007) Impact categories for life cycle assessment research of seafood production systems: review and prospectus. Int J Life Cycle Assess 12:414-421

Pelletier NL, Tyedmers PH, Sonesson U, Scholz A, Zeigler F, Flysjo A, Kruse SA, Cancino B, Silverman H (2009) Not all salmon are created equal: life cycle assessment (LCA) of global salmon farming systems. Environ Sci Technol 43:8730-8736
Pettersen J, Hertwich EG (2008) Critical review: life-cycle inventory procedures for long-term release of metals. Environ Sci Technol 42:4639-4647

Phong LT (2010) Dynamics of sustainability in Integrated AgricultureAquaculture Systems of the Mekong Delta. Ph.D thesis. Wageningen Institute of Animal Sciences, Wageningen University

Phong LT, de Boer IJM, Udo HMJ (2011) Life cycle assessment of food production in integrated agriculture-aquaculture systems of the Mekong Delta. Livest Sci 139:80-90

Roy P, Nei R, Orikasa T, Xu Q, Okadome H, Nakamura N, Shiina T (2009) A review of life cycle assessment (LCA) on some food products. J Food Eng 90:1-10

Seppälä J, Silvenius F, Grönroos J, Mäkkinen T, Silvo K, Storhammar E (2002) A life cycle assessment study of rainbow trout. Finnish Environmental Institute, Finish Game and Fisheries Research Institute. University of Jyväskylä, Finland

Seppälä J, Knuuttila S, Silvo K (2004) Eutrophication of aquatic ecosystems. A new method for calculating the potential contributions of nitrogen and phosphorus. Int J Life Cycle Assess 9:90-100

Seppälä J, Maximilian P, Johansson M, Hettelingh J-P (2006) Country-dependent characterisation factors for acidification and terrestrial eutrophication based on accumulated exceedance as an impact category indicator. Int J Life Cycle Assess 11:403-416

Silvenius F, Grönroos J (2003) Fish farming and the environmentResults of inventory analysis. Finnish Environment Institute 276. Helsinki, Finland

Sonesson U, Mattsson B, Nybrant T, Ohlsson T (2005) Industrial processing versus home cooking: an environmental comparison between three ways to prepare a meal. Ambio 34:414-421

Suh S, Lenzen M, Treloar GJ, Hondo H, Horvath A, Huppes G, Jolliet O, Klann U, Krewitt W, Moriguchi Y, Munksgaard J, Norris G (2004) System boundary selection in life-cycle inventories using hybrid approaches. Environ Sci Technol 38:657-664

Tlusty MF, Lagueux K (2009) Isolines as a new tool to assess the energy costs of the production and distribution of multiple sources of seafood. J Clean Prod 17:408-415

VDI (1997) Cumulative energy demand - terms, definitions, methods of calculation. In: Ingenieure VD. VDI-Richtlinien 4600, Düsseldorf, Germany

Weidema BP, Morteson B, Nielsen P, Hauschild M (1996) Elements of an impact assessment of wheat production. Technical University of Denmark, Lyngby, Institute for Product Development

WMO (World Meteorological Organization) (1999) Scientific assessment of ozone depletion: 1998. Global Ozone Research and Monitoring Project. Report 44. Geneva, Switzerland 